\title{
Polyurethane Foam Smoldering Supported by External Heating
}

\author{
TAKUJI SUZUKI, BAMBANG SUCAHYO and MASAAKI KAWAMATA \\ Department of Mechanical Engineering \\ lbaraki University, Ibaraki Japan \\ TOSHISUKE HIRANO \\ Department of Reaction Chemistry \\ The University of Tokyo, Tokyo Japan
}

\begin{abstract}
The temperature fluctuations during the smoldering spread in a rigid polyurethane foam were measured in order to explore the spread mechanisms and thermal structures of the smoldering combustion supported by external heating. The experiments were conducted under natural and forced draft conditions, and the effects of the heat source intensity $\mathrm{H}$ and the air supply content $\mathrm{Q}$ on smoldering were examined. It was found that smoldering spreads faster in the upward direction than the downward direction under natural draft conditions but that the spread rates become almost the same as $Q$ increases under forced draft conditions. The smoldering spread rate $\mathrm{Vs}_{\mathrm{s}}$ increases linearly as $\mathrm{H}$ or $\mathrm{Q}$ increases. The $\mathrm{Vs}_{\mathrm{s}}$ is proportional to the temperature gradient $(\mathrm{dT} / \mathrm{dx}) \mathrm{s}$ at the charring front, i.e., the heat flux transferred to the unburned solid. When the representative smoldering temperature $\mathrm{Tg}$ in the smoldering zone is larger than $300^{\circ} \mathrm{C}$, the smoldering spread is maintained, and Vs increases linearly as $\mathrm{Tg}$ increases.
\end{abstract}

KEYWORDS: Smoldering, polyurethane foam, spread rate, temperature gradient, heat flux, spread mechanism, external heating, air supply.

\section{INTRODUCTION}

Smoldering combustion plays an important role not only in the fire initiation but also in a part of the processes of the grown fires. Therefore, the characteristics of smoldering combustion have been major subjects for investigation in the fire safety field and various studies have been carried out [1-6]. However, many ambiguities remain because smoldering combustion is related to a variety of physical and chemical processes.

Smoldering combustion occurs as the result of a weak chemical reaction usually in a oxygen limited condition, and in many cases it is maintained with the support of external 
heating. Since smoldering combustion depends strongly on environmental conditions and on the properties of combustibles, it is necessary to examine the effects of external heat and oxygen concentration on smoldering for many kinds of combustible.

In the present study, therefore, the temperature fluctuations during the smoldering spread in a rigid polyurethane foam under natural draft and forced draft conditions were measured to explore the effects of external heating and air supply on smoldering. The variations in the smoldering spread rate with the heat source intensity and the air supply content were examined, and the relation between the smoldering spread rate and the heat flux to the unburned solid were clarified. The smoldering spread mechanisms are discussed by analyzing the heat balance in the unburned solid.

\section{EXPERIMENTAL}

A schematic diagram of the experimental apparatus is shown in Fig. 1. A rigid polyurethane foam cube with $30 \mathrm{~cm}$ sides is used. It is composed of twelve flat plates each $2.5 \mathrm{~cm}$ thick. The outer surfaces of the cube are covered with viscous cloth to prevent air from penetrating through the junctions between the polyurethane foam plates. A siliconite heater (diameter: $0.8 \mathrm{~cm}$, length of heat generating part: $25 \mathrm{~cm}$ ) is fixed horizontally in the center of the polyurethane foam cube.

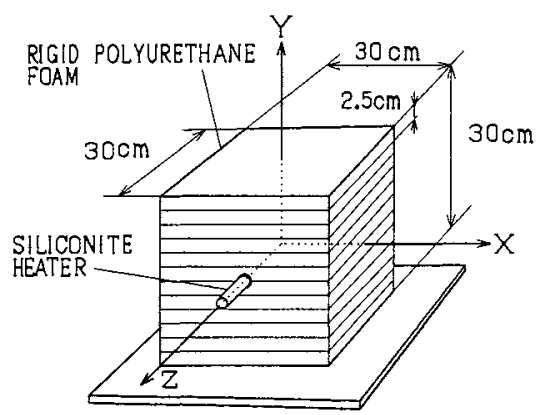

(a) Polyurethane foam cube and heater.

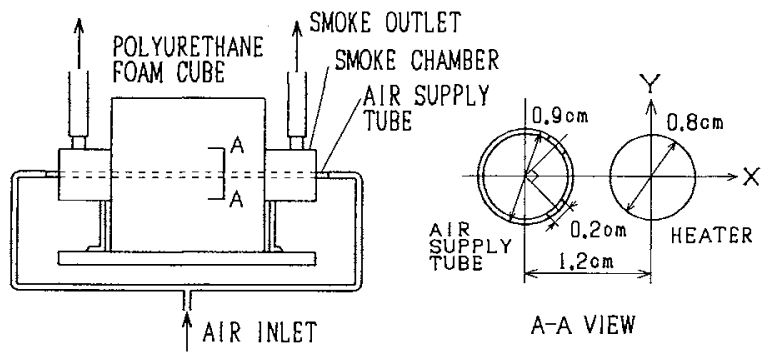

(b) Air supply system.

FIGURE 1 Experimental apparatus. 
For the experiments under natural draft conditions, the heater is supported at both ends by a pair of brass plates installed close to the polyurethane foam cube. When the heater is turned on, a smoldering front propagates inside the polyurethane foam cube. Except for the regions near the cube surfaces normal to the axis $\mathrm{Z}$ of the heater, the shape of a charring front is almost cylindrical. Smoke exits through the openings burned in the cube surfaces around the heater, and fresh air diffuses to some extent into the smoldering zone inside the cube. For the experiments under forced draft conditions, an air supply tube (outer diameter: $0.9 \mathrm{~cm}$, diameter of 22 nozzles: $0.2 \mathrm{~cm}$ ) is set close to the heater, and smoke chambers are fitted around the openings to prevent the diffusion of air through the openings into the smoldering zone. Air is supplied from an air reservoir through a flow meter to the air supply tube. The rigid polyurethane foam plates used in the experiments were a retarded porous combustible (density: $0.033 \mathrm{~g} / \mathrm{cm}^{3}$, thermal conductivity: $0.018 \mathrm{Kcal} / \mathrm{m} \mathrm{h}^{\circ} \mathrm{C}$, vapor permeability: $10^{-4} \mathrm{~g} / \mathrm{m} \mathrm{h} \mathrm{mmHg}$ ), which is widely used as a heat insulating material with low permeability.

In order to measure the temperature distribution and the smoldering spread rate , $12 \mathrm{C}-\mathrm{A}$ thermocouples (wire diameter: $0.18 \mathrm{~mm}$, sheath diameter: $1.0 \mathrm{~mm}$ ) were installed at predetermined positions on the horizontal axis $\mathrm{X}$ and the vertical axis $\mathrm{Y}$. The time constant of the thermocouples was $20 \mathrm{~ms}$ which was small enough for the response under the present experimental conditions. The temperatures were recorded at a time interval of $15 \mathrm{~s}$ with a high speed digital recorder. To determine the exact temperature at the charring front, the movement of the charring front was frozen by blowing nitrogen gas just after the heater was turned off.

\section{RESULTS AND DISCUSSION}

\section{Aspects of Smoldering}

A typical cross section of a polyurethane foam cube after smoldering is shown in Fig. 2.

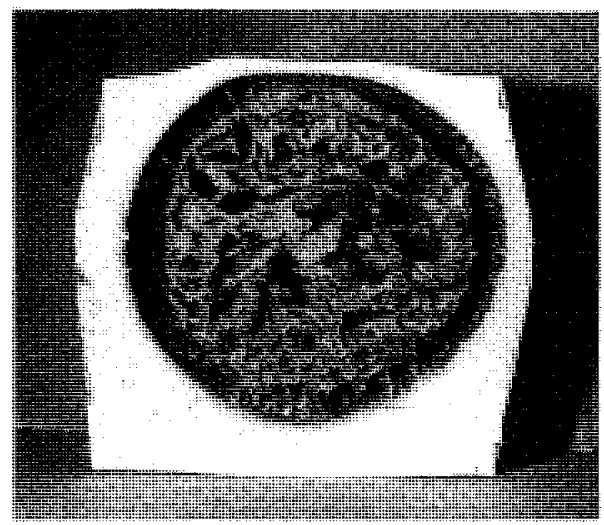

FIGURE 2 A photograph of the cross section of the polyurethane foam cube after smoldering in a natural draft. $\mathrm{H}=12.5 \mathrm{~W} / \mathrm{cm}, \mathrm{t}=30 \mathrm{~min}$. 
The experiment was conducted in a natural draft by heating at a heat source intensity $\mathrm{H}=12.5$ $\mathrm{W} / \mathrm{cm}$, and was stopped at a time $\mathrm{t}=30 \mathrm{~min}$ from the start. Netlike char was found in the burned region (smoldering zone) inside the charring front, i.e., the boundary between the unburned solid and the burned region. A thin char layer (thickness: approximately $0.05 \mathrm{~cm}$ ) was formed along the charring front, and a brown thermally affected layer was found in the unburned solid near the charring front. Since the boundary between the unburned solid and the burned region can be clearly recognized, it was defined as the charring front as a representative standard which positions the smoldering zone. Because the smoldering started in the center of the cross section, it can be estimated from the shape of the charring front, that the smoldering spreads faster upwards than downwards.

Figure 3 shows a typical temperature distribution near a horizontally spreading charring front at a position $X=5.0 \mathrm{~cm}$ from the heat source in a natural draft, where $\mathrm{x}$ is the distance from the charring front, $T$ is the temperature, the smoldering spread rate $V_{s}=0.0073 \mathrm{~cm} / \mathrm{s}$, and $\mathrm{H}=7.7 \mathrm{~W} / \mathrm{cm}$. In this case, the temperature $\mathrm{Ts}$ at the charring front is $221^{\circ} \mathrm{C}$. The $\mathrm{Ts}$ point is found to locate at almost the same position as the inflection point in the temperature profile. The Ts was confirmed to be independent of $V_{s}$ and to have a value of $220 \pm 10^{\circ} \mathrm{C}$ under the present experimental conditions. Since the temperature gradient (dT/dx)s at the unburned solid adjacent to the charring front and the representative smoldering temperature $\mathrm{T}_{\mathrm{g}}$ in the smoldering zone near the charring front seemed to be dominant factors regarding the heat transfer through the charring front, these values were examined in detail by measuring the temperature fluctuations during the smoldering spread. Since the location of the reaction zone is characterized by a maximum in the temperature profile [6], $\mathrm{Tg}$ was considered as a representative smoldering temperature which corresponds to the maximum temperature. However, as the maximum value can not be recognized clearly, $\mathrm{Tg}$ was defined as $T$ at $x=2 \Delta x=2(T s-T o) /(d T / d x)$ s as shown in Fig. 3. Therefore, it is inferred that in the region between $\mathrm{Ts}$ and $\mathrm{Tg}$ there is an oxidation reaction with heat generation.

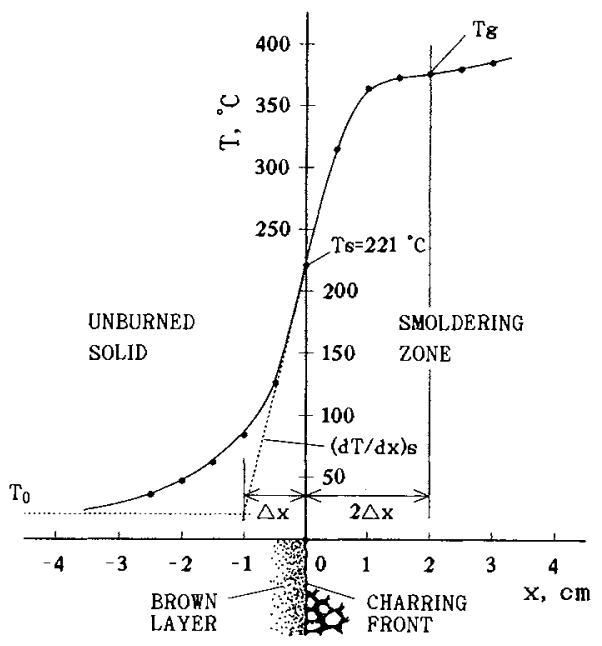

FIGURE 3 A typical temperature distribution near the charring front at $X=5.0 \mathrm{~cm}$. $\mathrm{H}=7.7 \mathrm{~W} / \mathrm{cm}$, horizontal spread in a natural draft, $\mathrm{Vs}_{\mathrm{s}}=0.0073 \mathrm{~cm} / \mathrm{s}$. 
Figures 4(a) and (b) show typical temperature fluctuations during upward and downward smoldering spreads under natural and forced draft conditions, which were supported by heating at the same heat source intensities. Based on these temperature-time $(T-t)$ diagrams, the smoldering spread rate $V_{s}$ is determined from the time which elapses between the charring front passing through two adjacent thermocouples and the distance $2.5 \mathrm{~cm}$ between the thermocouples. The charring front was adjudged to have passed when $\mathrm{T}$ reached $\mathrm{Ts}=220^{\circ} \mathrm{C}$ because Ts was confirmed to be constant. By measuring the temperature change rate $(\mathrm{dT} / \mathrm{dt})_{\mathrm{s}}$ at the passing of the charring front, $(\mathrm{dT} / \mathrm{dx}) \mathrm{s}$ is obtained as $(\mathrm{dT} / \mathrm{dt}) \mathrm{s} / \mathrm{Vs}$, and $\mathrm{Tg}$ is decided as $\mathrm{T}$ at the time interval $2 \Delta \mathrm{t}=2\left(\mathrm{~T}_{\mathrm{s}}-\mathrm{To}_{\mathrm{o}}\right) /(\mathrm{dT} / \mathrm{dt}) \mathrm{s}$ from the passing of the charring front. In a natural draft (Fig. 4(a)), it is found that the smoldering spreads faster upwards than downwards, and $\mathrm{T}$ over a wide region in the upper part of the smoldering zone (e.g. $\mathrm{T}$ for $\mathrm{Y}=-2.5,2.5,5.0$, and $7.5 \mathrm{~cm}$ at $\mathrm{t}=15 \mathrm{~min}$ ) is uniform and remains at a higher value than that in the lower part. On the other hand, in a forced draft at an air supply content $Q=10 \mathrm{l} / \mathrm{min}$ (Fig. 4(b)), the smoldering spread becomes faster, and the upward spread is slightly slower than the downward spread. $T$ in the smoldering zone near the air source and also the heat source ( $\mathrm{T}$ for $\mathrm{Y}=-2.5$ and $2.5 \mathrm{~cm}$ ) increase greatly, and $\mathrm{T}$ in the smoldering zone far from the sources ( $T$ for $Y=-10.0$ and $10.0 \mathrm{~cm}$ ) become almost the same. These facts suggest that the air supply greatly accelerates the heat generation, i.e., the chemical reaction in the smoldering zone, and affects equally both the upward and the downward smoldering spreads.

\section{Spread Rate}

Typical variations in $\mathrm{V}_{\mathrm{s}}$ with the distance $\mathrm{R}$ from the heat source for upward, downward, and horizontal spreads are shown in Fig. 5(a), (b), and (c), respectively. Vs increases rapidly to its maximum value in the initiation region $(R<2.5 \mathrm{~cm})$ near the heat source and then

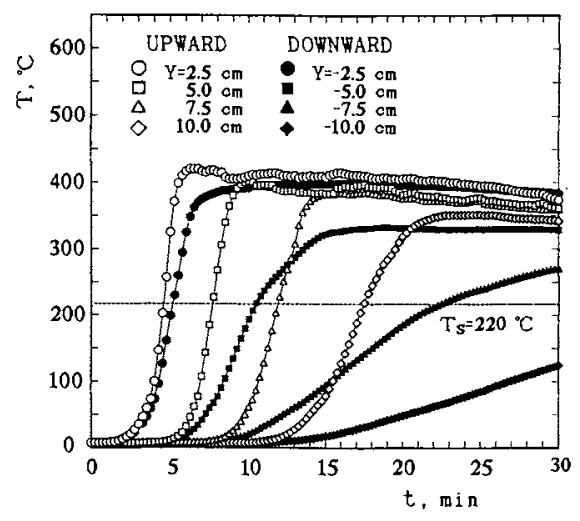

(a) In natural draft.

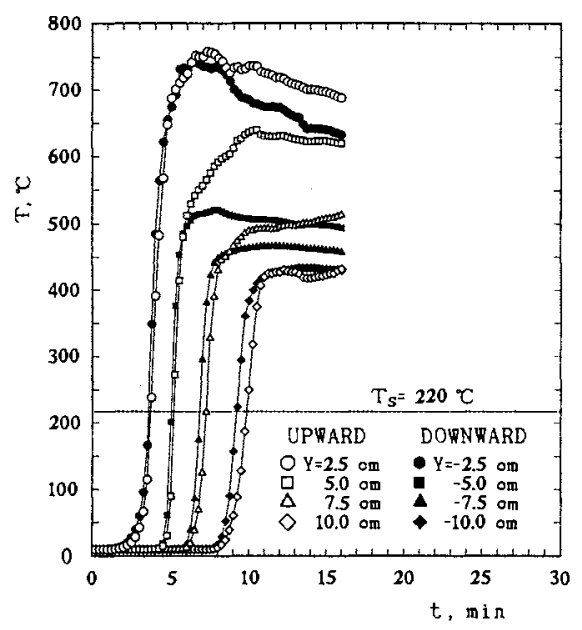

(b) In forced draft, $Q=10 \mathrm{l} / \mathrm{min}$.

FIGURE 4 Typical temperature fluctuations during upward and downward smoldering spreads under natural and forced draft conditions, $\mathrm{H}=7.7 \mathrm{~W} / \mathrm{cm}$. 
decreases gradually as $\mathrm{R}$ increases. Therefore, the results obtained in the normal region (2.5 $\mathrm{cm} \leq \mathrm{R} \leq 10.0 \mathrm{~cm}$ ) are discussed. In the present model of smoldering, as the heat source intensity was kept at a constant value, the heat flux from the heater to the smoldering zone decays with the radial distance and so $V_{s}$ basically decreases as $\mathrm{R}$ increases. In a natural draft at $\mathrm{H}=7.7 \mathrm{~W} / \mathrm{cm}$ (Fig. 5(a)), $\mathrm{Vs}$ of the upward spread is larger than that of the others for the same distance $R$. When the heating is increased to $H=21.0 \mathrm{~W} / \mathrm{cm}$ (Fig. $5(\mathrm{~b})$ ), Vs of all three spread directions increase together. For a forced draft at $Q=101 / \mathrm{min}$ (Fig. 5(c)), Vs of each spread direction becomes larger than that when the heating is increased in a natural draft (Fig. 5(b)).

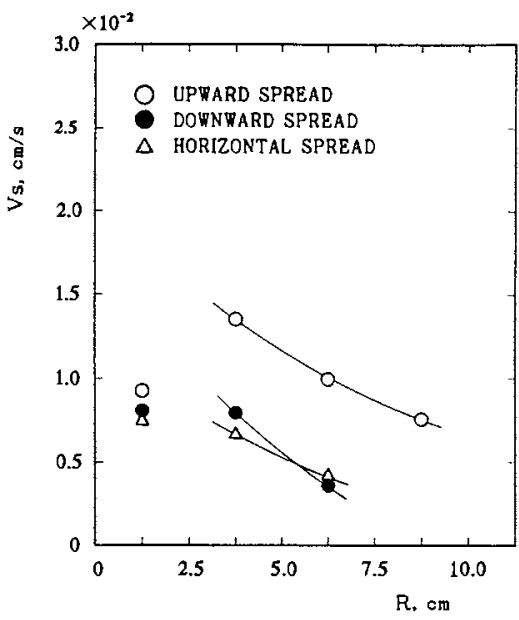

(a) In natural draft, $\mathrm{H}=7.7 \mathrm{~W} / \mathrm{cm}$.

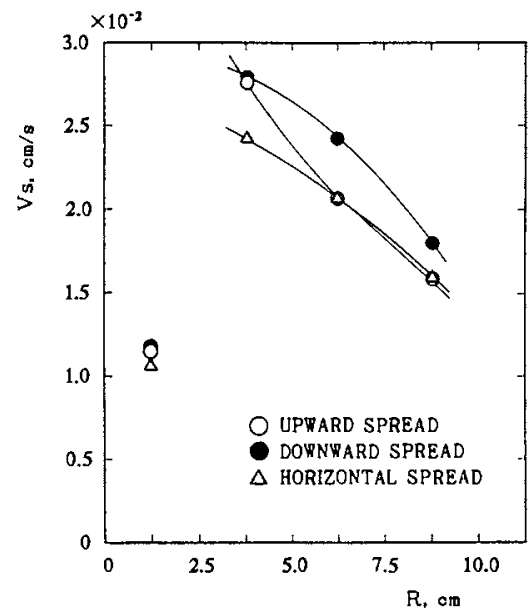

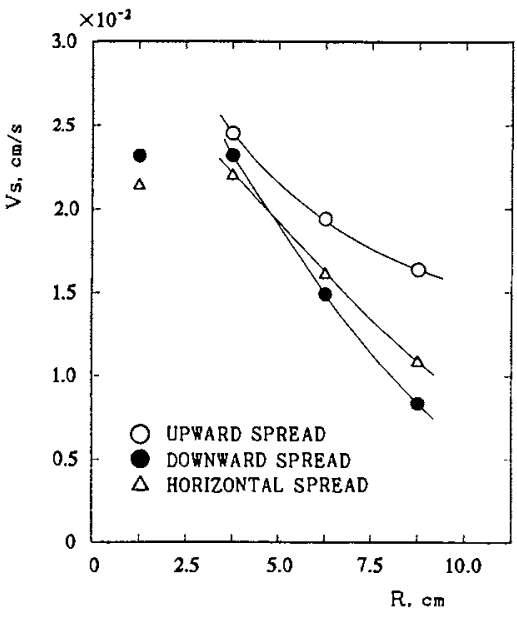

(b) In natural draft, $\mathrm{H}=21.0 \mathrm{~W} / \mathrm{cm}$.

(c) In forced draft, $\mathrm{H}=7.7 \mathrm{~W} / \mathrm{cm}, \mathrm{Q}=10 \mathrm{l} / \mathrm{min}$.

FIGURE 5 Variations in smoldering spread rate with the distance from the heat source. 
In order to explore the effects of external heating and air supply on smoldering, we examined variations in $\mathrm{Vs}$ at a representative location $(\mathrm{R}=6.25 \mathrm{~cm})$. Figure 6 shows the variations in $V s$ at $R=6.25 \mathrm{~cm}$ with $\mathrm{H}$ for upward, downward, and horizontal spreads under natural draft conditions. Vs of each spread direction is found to increase linearly with $H$. Vs of the upward spread is twice that of the downward spread throughout the present experimental range of $\mathrm{H}$. As seen in Fig. 4(a), the temperatures in the wide region located in the upper part of the smoldering zone remain at higher values than those in the lower part. The formation of such a temperature field is supposed to depend on the natural convection, i.e., buoyant flow in the smoldering zone and to cause the difference in Vs with the spread direction as discussed in previous studies $[4,6]$.

The variations in $\mathrm{Vs}$ at $\mathrm{R}=6.25 \mathrm{~cm}$ with $\mathrm{Q}$ for upward, downward, and horizontal spreads at $\mathrm{H}=7.7 \mathrm{~W} / \mathrm{cm}$ are shown in Fig. 7. In the $\mathrm{Q}$ range lower than $11 / \mathrm{min}, \mathrm{Vs}$ of the upward spread is larger than that of the downward spread, and the difference between them decreases as $Q$ increases. Since $V s$ of each spread direction for $Q=0$ (no air supply) corresponds with that obtained in a natural draft for $\mathrm{H}=7.7 \mathrm{~W} / \mathrm{cm}$ shown in Fig. 6, it can be inferred that there was only a slight diffusion of air through the openings into the smoldering zone under natural draft conditions. In the $Q$ range above $21 / \mathrm{min}$, the differences in $V_{s}$ among the three spread directions are not seen clearly, and their mean value is found to increase linearly with $\mathbf{Q}$. As discussed above, the air supply greatly accelerates the heat generation in the smoldering zone and causes the increase in $V_{s}$. In this range of $Q$, since the air is ejected upwards and downwards from fine nozzles at a considerable velocity, the effects of the heat generated by the air supply on Vs in both directions are balanced, even though the buoyant flow seems to affect Vs to some extent. These facts imply that the heat release rate in the smoldering zone directly proportional to the oxidizer mass flux into the reaction zone.

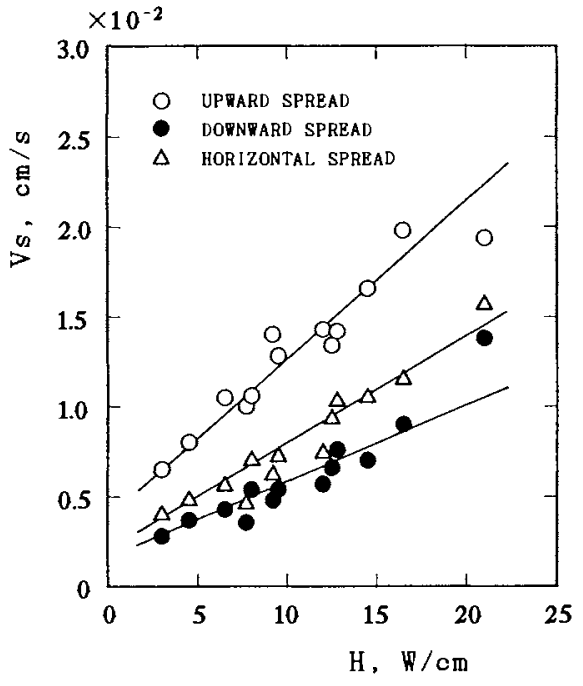

FIGURE 6 Variations in $\mathrm{Vs}$ at $\mathrm{R}=6.25 \mathrm{~cm}$ with the heat intensity in natural draft.

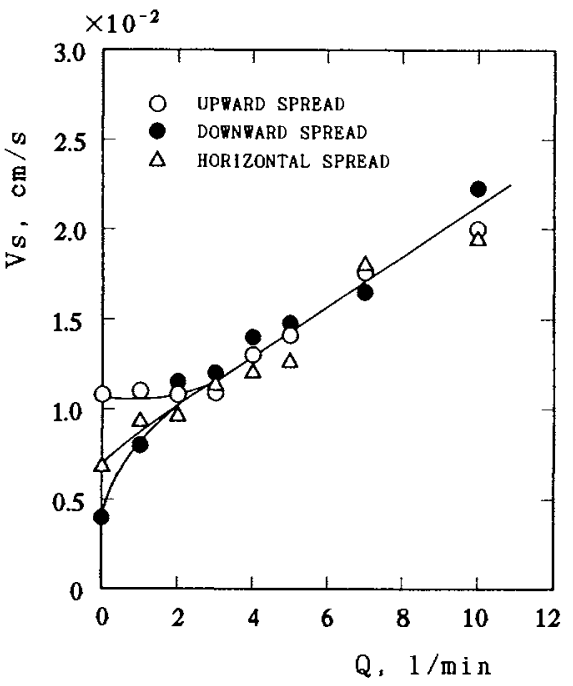

FIGURE 7 Variations in $\mathrm{Vs}$ at $\mathrm{R}=6.25 \mathrm{~cm}$ with the air supply content. $H=7.7 \mathrm{~W} / \mathrm{cm}$. 
The relations between Vs and (dT/dt)s for natural and forced draft conditions are shown separately in Fig. 8 (a) and (b). The relation under natural draft conditions is found to be exactly the same as that under the forced ones, and these relations can be expressed as $(\mathrm{dT} / \mathrm{dt}) \mathrm{s} \propto \mathrm{Vs}^{2}$. Therefore, it is inferred that the thermal structures near the charring front and the mechanisms of the smoldering spread are independent of the conditions of the external heating and the air supply.

The relation between $V_{s}$ and $(d T / d x)$ s was examined based on the relations between $V_{s}$ and $(\mathrm{dT} / \mathrm{dt}) \mathrm{s}$, and the results are shown in Fig. 9. It can be confirmed that $\mathrm{Vs}_{\mathrm{s}}$ is proportional to $(\mathrm{dT} / \mathrm{dx}) \mathrm{s}$ throughout the present experimental conditions in the wide ranges of $\mathrm{H}$ and $\mathrm{R}$. This relation is given as

$\mathrm{Vs}=\mathrm{K}\left(\frac{\mathrm{dT}}{\mathrm{dx}}\right)_{\mathrm{s}}$

where, $\mathrm{K}=5.0 \times 10^{-5} \mathrm{~cm}^{2} / \mathrm{s}^{\circ} \mathrm{C}$.

Since the heat transfer in the rigid polyurethane foam with low permeability is mainly as a result of heat conduction, the heat flux qs at the unbumed solid adjacent to the charring front can be expressed as $q s=\lambda(\mathrm{dT} / \mathrm{dx}) \mathrm{s}$, where $\lambda$ is thermal conductivity of the unburned solid.

Figure 10 shows the relation between $\mathrm{Vs}_{s}$ and $\mathrm{Tg}$ for natural and forced draft conditions. At $\mathrm{Tg}$ values above $300{ }^{\circ} \mathrm{C}$, the smoldering spread can be maintained, and $\mathrm{Vs}$ increases linearly as $\mathrm{Tg}$ increases. It can be seen that $\mathrm{Vs}$ is approximately proportional to the temperature difference $(\mathrm{Tg}-\mathrm{Ts})$. Although the heat transfer mode in the smoldering zone is

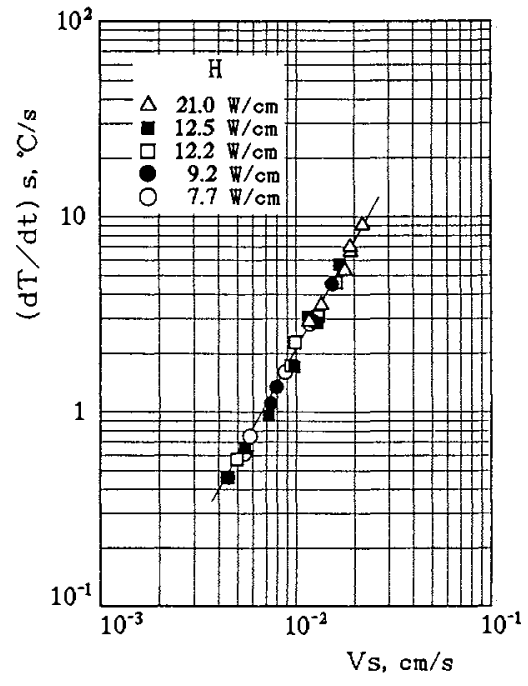

(a) In natural draft.

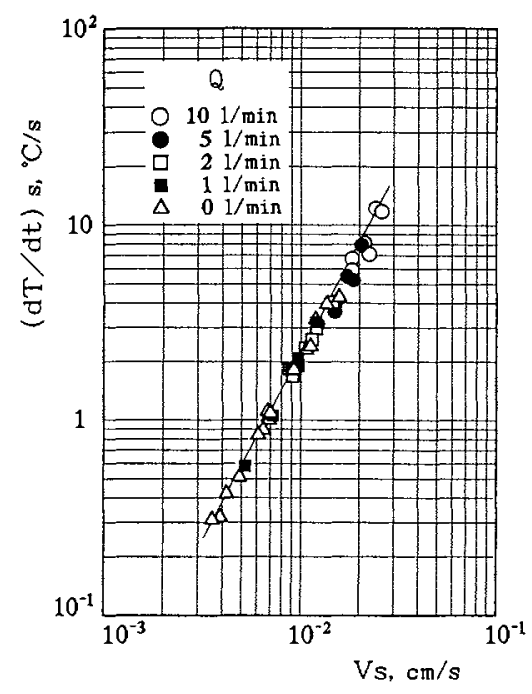

(b) In forced draft, $\mathrm{H}=7.7 \mathrm{~W} / \mathrm{cm}$.

FIGURE 8 Relations between Vs and (dT/dt)s. 
complicated by the thermal decomposition and the chemical reaction, the heat release rate in the smoldering zone near the charring front must be dominant for Vs. Therefore, it can be inferred that the heat release rate at the chemical reaction is closely related to ( $\mathrm{Tg}-\mathrm{Ts})$. The $\mathrm{T}_{\mathrm{g}}$ is found to be a very useful standard by which to predict properly the smoldering spread rate even if the overall smoldering field is complicated.

\section{Heat Balance in the Unbumed Solid}

Throughout the present experiments, it was found that $\mathrm{V}_{s}$ is proportional to $(\mathrm{dT} / \mathrm{dx})$ s, i.e., the heat flux qs at the unburned solid adjacent to the charring front and is approximately proportional to the temperature difference $(\mathrm{Tg}-\mathrm{Ts})$. The mechanisms of the smoldering spread could be further explored by analyzing the relations between $V_{s}$ and these values. It is difficult to analyze the relation between $V_{s}$ and $(T g-T s)$, because there are many unknown factors in the smoldering zone such as the mode of heat transfer, the process of chemical reaction, the characteristics of gas phase and burmed solid. However, it is comparatively easy to analyze the relation between $\mathrm{Vs}$ and $(\mathrm{dT} / \mathrm{dx})$ s because the dominant heat transfer mode in the unburned solid must be heat conduction and the characteristics of the unburned solid can be assumed not to change very much.

In order to analyze the heat balance in the unburned solid near the charring front, the distribution of temperature $T$ and coordinate $x$ shown in Fig. 3 are referred to. If we ignore heat losses to the environment, the thermal field can be assumed to be one dimensional. In the frame of reference which is moving with the smoldering front, a steady thermal field is formed in the flow of unburned solid from left to right at the same velocity as Vs. Under such conditions, the one dimensional form of the energy conservation equation concemed with conduction and convection terms is given as $[6,7]$

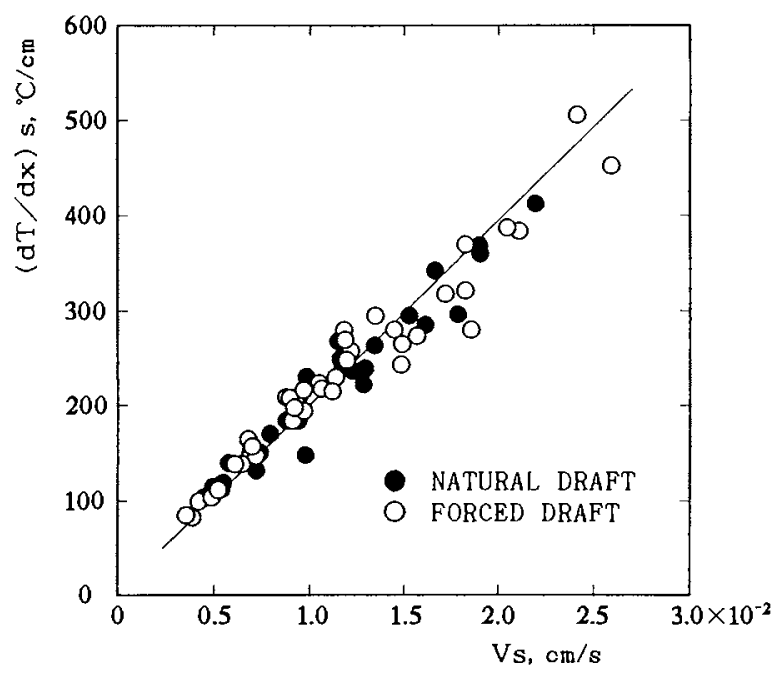

FIGURE 9 Relation between $V_{S}$ and $(d T / d x) s$. 
$\rho C_{p} V s \frac{d T}{d x}=\lambda \frac{d^{2} T}{d x^{2}}$

where, $\rho$ : density

$C_{p}:$ specific heat capacity

$\lambda$ : thermal conductivity

boundary conditions:

$\mathrm{x}=-\infty \quad: \mathrm{T}=\mathrm{T}_{\mathrm{o}}$

$x=x s=0: T=T s, d T / d x=(d T / d x) s$.

By integrating Eq. (2) with $x$, the following equations are obtained.

$\mathrm{T}=\mathrm{T}_{\mathrm{o}}+\frac{\lambda}{\rho \mathrm{C}_{\mathrm{p}} \mathrm{Vs}_{\mathrm{s}}} \frac{\mathrm{dT}}{\mathrm{dx}}$

$V_{s}=\frac{\lambda}{\rho C_{p}\left(T_{s}-T_{0}\right)}\left(\frac{d T}{d x}\right)_{s}=K\left(\frac{d T}{d x}\right)_{s}$

where, $\quad K=\frac{\lambda}{\rho C_{p}\left(T_{s}-T_{0}\right)}$.

From $\mathrm{Eq}$. (5), $\mathrm{K}$ is found to be inversely proportional to ( $\mathrm{Ts}-\mathrm{T}_{0}$ ). However, $\mathrm{K}$ was almost constant because the experiments were conducted at room temperature $\left(\mathrm{T}_{\mathrm{o}}=10-15^{\circ} \mathrm{C}\right)$. Thus, it was confirmed that $\mathrm{Vs}$ can be easily predicted if (dT/dx)s or qs are known. On the

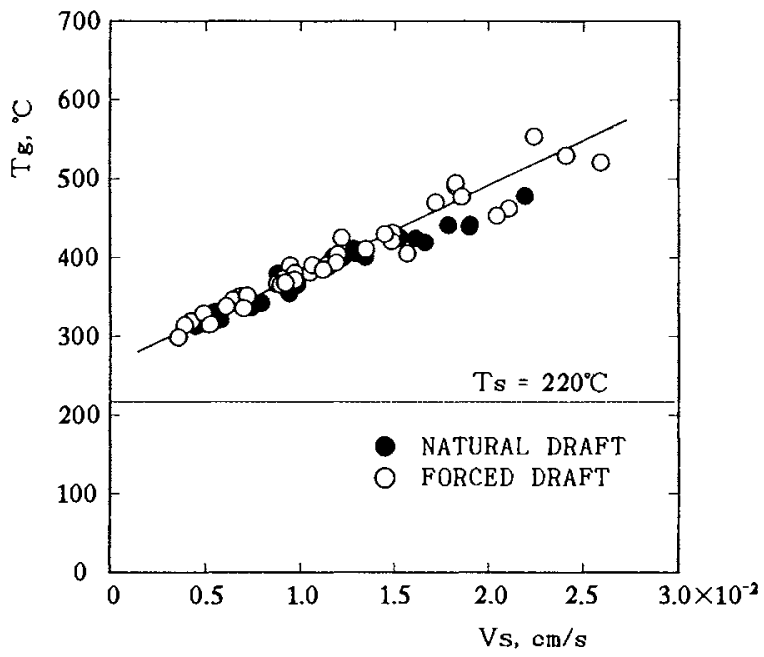

FIGURE 10 Relation between $\mathrm{Vs}$ and $\mathrm{Tg}$. 
other hand, $(\mathrm{dT} / \mathrm{dx}) \mathrm{s}$ was found to be closely related to ( $\mathrm{Tg}-\mathrm{Ts})$ from the results shown in Figs. 9 and 10, although it is supposed that the heat transfer mode in the smoldering zone is different from that in the unburned solid.

These results have provided further insight into the Vs dependence on the heat flux transferred to the unburned solid and the spread mechanisms for the present experiments which represent features of one type of real smoldering fire. However, in order to complete the analysis of the spread mechanisms, the energy balance in the smoldering zone must be discussed including the unknown factors such as the chemical reaction, the heat transfer mode and the characteristics of burned material. A further study of this subject should enable us to accomplish this.

\section{CONCLUSIONS}

The temperature fluctuations during the smoldering spread in a rigid polyurethane foam have been measured under natural draft and forced draft conditions. The effects of external heating and air supply on the smoldering spread rate were examined, and the spread mechanisms and thermal structures of the smoldering were discussed. The results are summarized as follows:

(1) Based on the temperature distributions near the charring front, the temperature Ts at the charring front was confirmed to be independent of the smoldering spread rate $V_{s}$ and to have a value of $220 \pm 10^{\circ} \mathrm{C}$ under the present experimental conditions.

(2) The variations in $\mathrm{Vs}$ with heat source intensity $\mathrm{H}$ for upward, downward, and horizontal spreads under natural draft conditions were examined. Vs of each direction increases linearly with $\mathrm{H}$, and $\mathrm{Vs}$ of the upward spread is twice that of the downward spread.

(3) The variations in $V_{s}$ with air supply content $Q$ were examined for the three spread directions. For $Q$ values below $1 \mathrm{l} / \mathrm{min}, V_{s}$ of the upward spread is larger than that of the downward spread, and for $Q$ values above $21 / \mathrm{min}$, no differences are observed in $\mathrm{Vs}$, and its mean value increases linearly with $Q$.

(4) The $V s$ is confirmed to be proportional to the temperature gradient (dT/dx)s at the charring front, i.e., the heat flux transferred to the unburned solid near the charring front.

(5) When the representative smoldering temperature $\mathrm{Tg}$ in the smoldering zone near the charring front is larger than $300^{\circ} \mathrm{C}$, the smoldering spread can be maintained, and $\mathrm{Vs}$ increases linearly as $\mathrm{T}_{\mathrm{g}}$ increases.

(6) To discuss the mechanisms of the smoldering spread, the relation between $\mathrm{Vs}$ and $(\mathrm{dT} / \mathrm{dx}) \mathrm{s}$ was analyzed using a simple model based on the heat balance in the unbumed solid.

\section{ACKNOWLEDGMENT}

The authors would like to express their sincere thanks to Messrs. K. Hirayama, T. Miyashita and Le Ky Trung for their help in conducting experiments. 


\section{REFERENCES}

1. Moussa, N. A., Toong, T. Y. and Garris, C. A., "Mechanisms of Smoldering of Cellulosic Materials", Sixteenth Symposium (International) on Combustion, The Combustion Institute, pp. 1447-1457, 1976.

2. Ohlemiller, T. J. and Rogers, F. E., "A Survey of Several Factors Influencing Smoldering Combustion in Flexible and Rigid Polymer Foams", J. Fire and Elammability, 2, 489-510, 1978.

3. Ohlemiller, T. J. and Lucca, D. A., "An Experimental Comparison of Forward and Reverse Combustion", Combustion and Flame , 54, 131-147, 1983.

4. Ohlemiller, T. J., "Modeling of Smoldering Combustion Propagation", Progress in Energy and Combustion Science, 11, 277-310, 1985.

5. Dosanjh, S. S., Pagni, P. I. and Fernandez-Pello, A. C., "Forced Concurrent Smolder in Combustion", Combustion and Flame, 68, 131-142, 1987.

6. Torero, A. L., Fernandez-Pello and Kitano, K., "Opposed Forced Flow Smoldering of Polyurethane Foam", Combustion Science and Technology, 91, 95-117, 1993.

7. Fernandez-Pello, A. C. and Hirano, T., "Controlling Mechanisms of Flame Spread", Combustion Science and Technology, 32, 1-31, 1983. 